\title{
Correspondence
}

\section{No coincidence}

DEAR EDITOR,

A 'gleaning' in the December 1986 Gazette points out the following calculator property:

$$
\begin{array}{lll}
7 & 8 & 9 \\
4 & 5 & 6 \\
1 & 2 & 3
\end{array}
$$

Display (either in order or in reverse order) the three digits from any row, column or main diagonal. Follow these by the same three digits in reverse order (e.g. 951159). The resulting number is always divisible by 37 .

This is no coincidence. For let $a, a+d, a+2 d$ be any three integers in arithmetic progression. Then

$$
\begin{aligned}
& a \cdot 10^{5}+(a+d) \cdot 10^{4}+(a+2 d) \cdot 10^{3}+(a+2 d) \cdot 10^{2}+(a+d) \cdot 10+a \cdot 1 \\
& \quad=a\left(10^{5}+10^{4}+10^{3}+10^{2}+10+1\right)+d\left(10^{4}+2 \cdot 10^{3}+2 \cdot 10^{2}+10\right) \\
& \quad=111111 a+12210 d=1221(91 a+10 d) .
\end{aligned}
$$

So not only is the number divisible by 37 , but by $1221(=3 \times 11 \times 37)$.

Yours sincerely, ERIC NUMMELA

New England College, Arundel, Sussex BN18 ODA

\section{The untrained teacher's progress}

\section{DEAR EDITOR,}

I thought that your readers might be interested in this 'gleaning' from The Diaries of Lewis Carroll (C. L. Dodgson):

Jan 29 1856: Breakfasted with Swabey to arrange about teaching in his school [St Aldate's]. We settled that I am to come at 10 on Sunday, and at 2 on Tuesdays and Fridays to teach sums. I gave the first lesson there today, to a class of eight boys, and found it much more pleasant than I expected. The contrast is very striking between town and country boys; here they are sharp, boisterous, and in the highest spirits--the difficulty of teaching being, not to get an answer, but to prevent all answering at once.

$\mathrm{Feb} 1$ : The master at St Aldate's School asked if I would join the first class of girls with the boys. I tried it for today, but I do not think they can be kept together, as the boys are much the sharpest. This made a class of fifteen: I went on with 'practice' as before.

Feb 5: Varied the lesson at the school with a story, introducing a number of sums to be worked out.

Feb 8: The school class noisy and inattentive - the novelty of the thing is wearing off, and I find them rather unmanageable.

Feb 15: School again noisy and troublesome-I have not yet acquired the arts of keeping order.

Feb 26: Class again noisy and inattentive-it is very disheartening, and I almost think I had better give up teaching there for the present.

Feb 29: Left word at the school that I shall not be able to come again for the present. I doubt if I shall try again next term: the good done does not seem worth the time and trouble.

Faculty of Mathematical Studies, University of Southampton, SO9 $5 \mathrm{NH}$

Yours sincerely, GEOFFREY HOWSON 